\title{
Genetic structuring of Ephedra an important medicinal plant from low to high altitudinal zones of Balochistan, Pakistan
}

\author{
ABDUL BASIT ${ }^{1}$, SHAZIA SAEED ${ }^{1, \boldsymbol{v}}$, ALIA AHMED ${ }^{1}$, NIZAM BALOCH ${ }^{2}$, ASIF ZAHID ALI ${ }^{2}$ \\ ${ }^{1}$ Department of Botany, University of Balochistan. Quetta 87300, Pakistan. Tel./fax.: +92-81-921-1264. `email: shazia_botany@yahoo.com \\ ${ }^{2}$ Department of Chemistry, University of Balochistan. Quetta 87300, Pakistan
}

Manuscript received: 17 November 2020. Revision accepted: 12 January 2021.

\begin{abstract}
Basit A, Saeed S, Ahmed A, Baloch N, Ali AZ. 2021. Genetic structuring of Ephedra an important medicinal plant from low to high altitudinal zones of Balochistan, Pakistan. Biodiversitas 22: 713-718. The current study is based on the genetic structuring of three Ephedra species compared to the morphological and phytochemical investigation. Ephedra is a significant, medicinally important genus growing naturally in arid and semi-arid regions of Balochistan Pakistan. Resolving the taxonomic identification of Ephedra species genetic variability was estimated by using Random Amplified Polymorphic DNA and Inter-Simple Sequence Repeats. Higher values revealed that $E$. foliata possess high genetic diversity. Less diversity was observed within Takatu Mountain Range population. Diversity in Nushki region was found higher than the Takatu Mountain Range. The genetic diversity was maintained within the populations of all three species of Ephedra at Hazarganji-Chiltan National Park. That may be due to the less anthropogenic activity in conserved region of the Park. Assessment and conservation of genetic diversity through molecular markers is essential that could be used as a key to conserve genetic variability. This study is the first endeavor to estimate genetic and phytochemical diversity within and among diverse populations of Ephedra from the region to the best of our knowledge. Genetic diversity can be used as key tool for further development of a management plan for ex situ reproduction and in situ conservation
\end{abstract}

Keywords: Ephedra, genetic diversity, Hazarganji-Chiltan National Park, morphological diversity, Nushki, phytochemicals, Quetta

\section{INTRODUCTION}

The genus Ephedra is a dioecious perennial evergreen shrub represented by five species in Balochistan, found from low elevation to high elevation zone comprising $E$. procera, E. gerardiana, E. intermedia, E. sarcocarpa and E. ciliate (Saeed et al. 2015).

Ephedra major subsp. procera (C.A. Mey.) Bornm (synonym: E. procera) found in Balochistan. The Ephedra is a source of various medicinal phytoconstituents, derived from flavano-flavonol and Ephedrannin. Chemical composition regarding TAC, TPC, and TFC using spectrophotometry were investigated from different parts of Ephedra species (Ibragic and Sofić 2015).

Ephedra ciliata Fischer and C. A.Mey. is a synonym of E. foliata Boiss. It is widely distributed in Afghanistan, Pakistan, Iran, and native to North Africa and Southwest Asia (Abd El-Ghani et al. 2017). Traditionally, E. ciliata is used to cure respiratory disorders including nasal congestion, asthma and flu. The taxon is also used to treat rheumatoid arthritis (Ahmad et al. 2014). Quercetin-rich methanol extract of E. ciliata has also been found efficient against healing wounds, hence used as a source of antioxidant, antimicrobial, and anti-inflammatory (Yaseen et al. 2020).

Ephedra intermedia is spread through north and northwest of China and also distributed in arid region of Central Asia. This species is usually shrub or subshrub. Densely branched, prostrate or erect stems, commonly three or rarely two connate leaves attached at the node, stems and were bluish-green in color. (Kitani et al. 2011)
Traditionally E. intermedia are used to treat respiratory tract diseases. The taxon is also utilized as a diet supplement against obesity, besides its use as a medicine. Ephedra species have a controversial taxonomy due to their similar morphological features that are not enough to characterize the taxa.

Hence, the main objective of the current study was to collect Ephedra spp. growing in diverse ecological zones of Balochistan, Pakistan and fingerprint the genetic variability, morphological and biochemical variation within and among various populations by using randomly amplified polymorphic DNA (RAPD), and Inter-simple Sequence Repeats (ISSR) and biochemical and morphological markers. The genetic diversity plays a key role for the survival of any species to its environment. The assessment of genetic diversity can be done by the use of morphological, biochemical, and molecular markers. Environmental variables influence morphological traits thus exhibiting a low level of diversity. Hence a consistent correlation was not found for a particular species and environmental stability (Aboukhalid et al. 2017). Different molecular markers can determine the level of polymorphism and genetic diversity for medicinally important plant species. The existing genetic diversity, systematic analysis and the importance of the plants is the key to conserve the taxa. Therefore, keeping in view all described parameters, the current project was designed to measure genetic diversity of medicinally important three species of Ephedra the molecular variance in segregated populations belonging to varied geo-environmental regions. 


\section{MATERIALS AND METHODS}

\section{Field surveys}

Field surveys were carried out over two years (from 2018 to 2019) in diverse ecological zones of Balochistan, Pakistan where Ephedra spp. has been reported. Field methods were drawn from (Saeed et al. 2017). Ephedra spp. diversity was surveyed in 3 different localities, i.e., Takatu Mountain Range, Hazarganji-Chiltan National Park, and Nushki (Figure 1). Plant specimens were collected, identified, and described morphologically. The voucher specimens were deposited in the Botany Department, University of Balochistan, Quetta, Pakistan herbaria for future reference (Table 1).

\section{Morphology}

The various morphological characters for phylogenetic analysis were measured, namely flower color, stem color, cone color, seed color, and stem surface. Different magnifiers were used for observations of various parts.

\section{Phytochemical variation}

Total phenolic and flavonoid contents were estimated by using spectrophotometric quantification. (i) Flavonoids: The method of Ordonez et al. (2006) was used to analyze flavonoid contents. The amount of flavonoid measured at $420 \mathrm{~nm}$ absorbance. Total flavonoids contents were assessed by the quercetin (mg/g) equation ( $\mathrm{Y}=0.0255 \times \mathrm{R} 2=0.9812)$. (ii) Total phenolic contents: The method by Slinkard and Singleton (1977) is used for the analysis. The total phenolic content was calculated at 765 $\mathrm{nm}$ absorbance. Total phenolic contents were expressed as $\mathrm{mg} / \mathrm{g}$ tannic acid equivalent by the equation $(\mathrm{Y}=0.1216 \times \mathrm{R} 2=0.9365)$.

\section{Genetic diversity}

The DNA extraction was carried out by using CTAB method with few modifications. The PCR reaction was carried out using Saeed et al. (2017). A total of twenty primers (RAPD and ISSR) were used.

\section{Statistical analysis of data}

For genetic diversity analysis, molecular markers data were scored as 1 (present) and 0 (absent). The data were subjected to generate clusters based on similarity matrices by using software NTSYS 2.10.

\section{RESULTS AND DISCUSSION}

This is the first comprehensive report on the morphological, chemical, and molecular diversity of three medicinally important Ephedra species from low elevation semi-deserted area to high mountainous regions of Balochistan, Pakistan.

\section{Morphological diversity}

Morphologically Ephedra is a complex genus difficult to be distinguished. Height of this shrub may range to $3 \mathrm{ft}$. Habit of this shrub is woody below and upright branches are herbaceous aromatic. Stem color varies from bright green to grayish-green (Table 2). while no variation found in flower color all were reported yellow. Cone color and seed color showed variation in all three species. No variation found in stem surface.

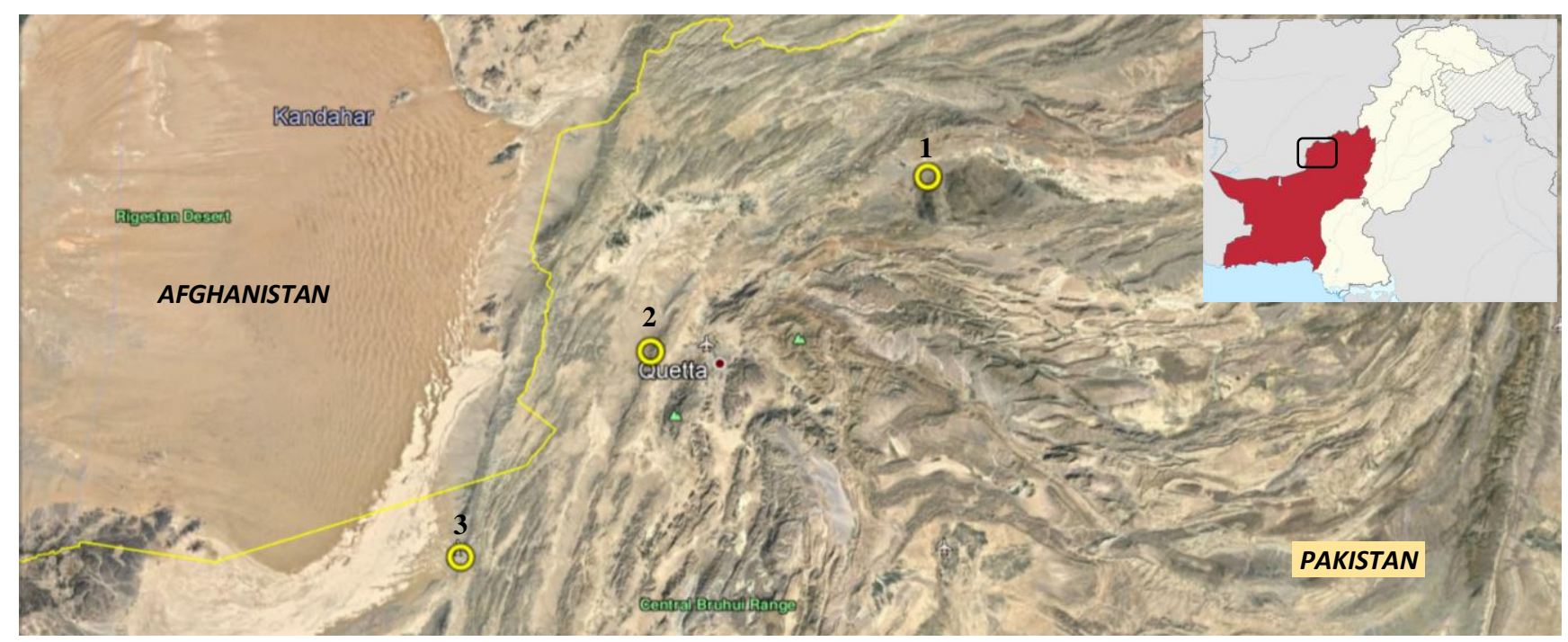

Figure 1. Map of study area in Balochistan, Pakistan. 1. Takatu Mountain Range, 2. Hazarganji-Chiltan National Park, 3. Nushki

Table 1. Ecological characteristics, altitudinal description, and date of collection of Ephedra specimen from the study in Balochistan, Pakistan

\begin{tabular}{|c|c|c|c|c|c|c|}
\hline Taxon name & $\begin{array}{l}\text { Plant } \\
\text { code }\end{array}$ & Locality & $\begin{array}{c}\text { Date of } \\
\text { collection }\end{array}$ & Coordinate & $\begin{array}{c}\text { Elevation } \\
\text { (m asl.) }\end{array}$ & Voucher no. \\
\hline E. major subsp. procera & $1-3$ & Takatu Mountain Range & 2019-06-15 & $30.17-39^{\circ} \mathrm{N} ; 67.01-02^{\circ} \mathrm{E}$ & $1660-3200$ & QUETTA000007 \\
\hline E. foliata & $4-6$ & Hazarganji-Chiltan NP & 2019-03-12 & $30.22-32^{\circ} \mathrm{N} ; 66.73-68^{\circ} \mathrm{E}$ & $1600-3000$ & QUETTA000049 \\
\hline E. intermedia & $7-9$ & Nushki & 2019-04-07 & $29.47-32^{\circ} \mathrm{N} ; 65.98-67^{\circ} \mathrm{E}$ & $1700-2600$ & QUETTA000042 \\
\hline
\end{tabular}


Table 2. Morphological characters of Ephedra spp.

\begin{tabular}{lclllc}
\hline Plant code & Flower color & Stem color & Cone color & Seed color & Stem surface \\
\hline 1 & Yellow & Green & Yellow & Yellowish-brown & Scabrid \\
2 & Yellow & Green & Yellowish-brown & Yellow & Scabrid \\
3 & Yellow & Green & Brownish gray & Dark brown & Scabrid \\
4 & Yellow & Light Green & Brown & Dark brown & Scabrid \\
5 & Yellow & Light Green & Light green & Yellow & Scabrid \\
6 & Yellow & Green gray & Light Brown & Yellowish brown & Scabrid \\
7 & Yellow & Lush Green & Dark brown & Yellow brown & Scabrid \\
8 & Yellow & Lush Green & Brown & Dellow & Scabrid \\
9 & Yellow & Lush green & Dark brown & Dark brown & Scabrid \\
\hline
\end{tabular}

Based on quantitative characters, cluster generated for all three species. The cluster analysis revealed that $E$. major subsp. procera and E. foliata are closely related, while E. intermedia clustered separately. Two major groups were found one with E. major subsp. procera and E. foliata and the second with E. intermedia (Figure 2).

\section{Genetic diversity}

In present study, two different marker systems i.e. RAPD and ISSR were used for the first time on three species of this significant genus Ephedra from Balochistan (Table 3). The size of amplified bands was 200 to $900 \mathrm{bp}$ for RAPD, 100 to 1000 bp of ISSR (Figures 3-4). We used combined RAPD and ISSR markers to generate dendrogram by cluster analysis. A combined marker system approach to detect polymorphism could be useful in removing errors and targeting various genome sites as previously used by (Saeed et al. 2020; Saeed et al. 2017).

Out of teste 20 makers, i.e. nine RAPD and six ISSR exhibited polymorphism and showed reproducible bands among Nine Ephedra accessions. Table 4 explains the characteristics of banding patterns obtained with primers. These fifteen primers amplified 128 loci and 72 were polymorphic (56\% polymorphism). The total number of RAPD and ISSR bands scored per primers also varied. Overall data revealed an average of 8.53 bands obtained per primer.

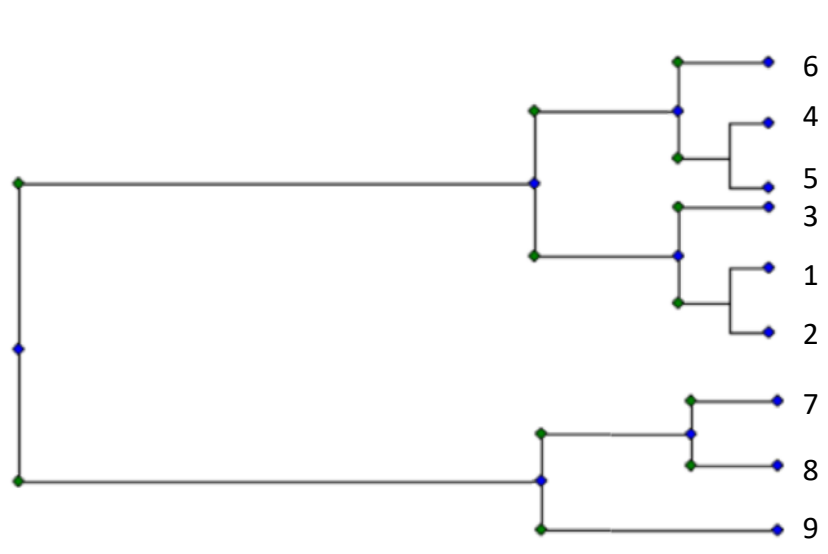

Figure 2. Tree diagram based on quantitative morphological characters of Ephedra spp. Note: Plant sample code refer to Table
Table 3. List of molecular markers used in analysis of genetic diversity

\begin{tabular}{|c|c|c|}
\hline Name of marker & Sequence & Size nucleotide \\
\hline \multicolumn{3}{|l|}{ RAPD } \\
\hline OPA-2 & TGCCGAGCTG & 10 \\
\hline OPA-3 & AGTCAGCCAC & 10 \\
\hline OPA-4 & AATCGGGCTG & 10 \\
\hline OPA-7 & GAAACGGGTG & 10 \\
\hline OPA-8 & GTGACGTAGG & 10 \\
\hline OPA-13 & CAGCACCCAC & 10 \\
\hline OPA-14 & CAGCACCCAC & 10 \\
\hline OPA-17 & GACCGCTTGT & 10 \\
\hline OPC-1 & GTTTCGCTCC & 10 \\
\hline OPC-6 & GAACGGACTC & 10 \\
\hline \multicolumn{3}{|l|}{ ISSR } \\
\hline UBC-808 & $(\mathrm{AG}){ }_{8} \mathrm{C}$ & 17 \\
\hline UBC-811 & $(\mathrm{GA})_{8} \mathrm{C}$ & 17 \\
\hline UBC-815 & $(\mathrm{CT})_{8} \mathrm{G}$ & 17 \\
\hline UBC-818 & $(\mathrm{CA})_{8} \mathrm{G}$ & 17 \\
\hline UBC-824 & $(\mathrm{TC})_{8} \mathrm{G}$ & 17 \\
\hline UBC-832 & $(\mathrm{AT})_{8} \mathrm{C}$ & 17 \\
\hline UBC-834 & $(\mathrm{AG})_{8}(\mathrm{CT}) \mathrm{T}$ & 19 \\
\hline UBC- 838 & $(\mathrm{TA})_{8} \mathrm{C}$ & 17 \\
\hline UBC-841 & $(\mathrm{GA})_{8} \mathrm{TC}$ & 18 \\
\hline UBC- 856 & (AC) ${ }_{8} \mathrm{TG}$ & 18 \\
\hline
\end{tabular}

Table 4. Details of polymorphic primers used in the study

\begin{tabular}{lcccc}
\hline Primer name & TA $\left({ }^{\circ} \mathbf{C}\right)$ & TB & P & PB\% \\
\hline OPA-2 & 36 & 5 & 4 & 80 \\
OPA-3 & 34 & 8 & 6 & 75 \\
OPA-4 & 34 & 11 & 6 & 55 \\
OPA-7 & 34 & 7 & 3 & 43 \\
OPA-8 & 36 & 5 & 3 & 60 \\
OPA-13 & 36 & 12 & 6 & 50 \\
OPA-14 & 34 & 6 & 4 & 67 \\
OPC-1 & 34 & 15 & 7 & 47 \\
OPC-6 & 36 & 11 & 5 & 45 \\
UBC-808 & 50 & 7 & 2 & 29 \\
UBC-811 & 52 & 5 & 2 & 40 \\
UBC-815 & 50 & 8 & 4 & 0.5 \\
UBC-824 & 50 & 8 & 7 & 87 \\
UBC-834 & 50 & 13 & 8 & 62 \\
UBC-841 & 52 & 7 & 5 & 71 \\
Total & & 128 & 72 & 56 \\
\hline
\end{tabular}

Note: TA $\left({ }^{\circ} \mathrm{C}\right)$ : annealing temperature, T: Total bands, P: Number of polymorphic bands, \% PB: percentage of polymorphism 


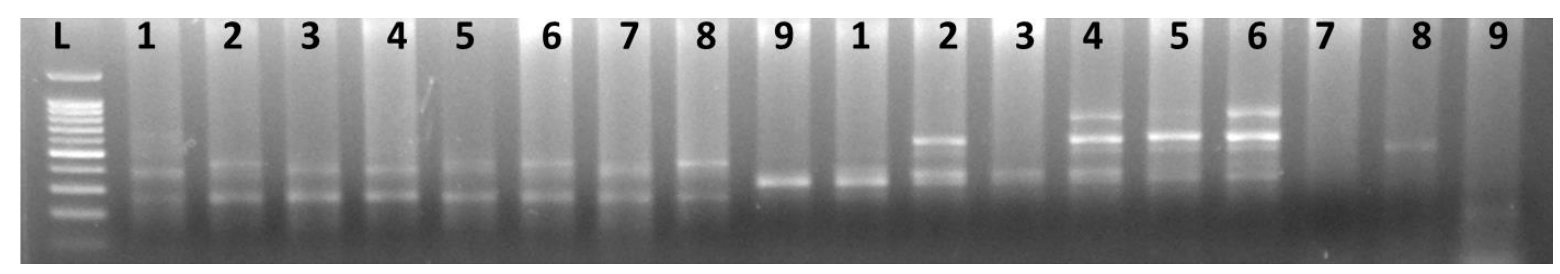

Figure 3. PCR amplification of Ephedra spp. of RAPD OPA-4-and OPC-6 population from lane 1-9. With 100 bp Leader

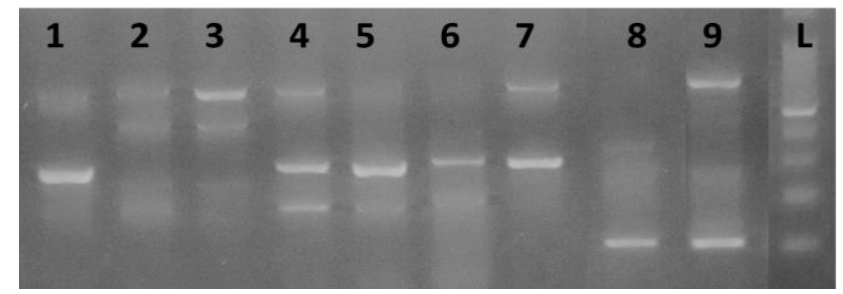

Figure 4. PCR amplification of Ephedra spp. of ISSR- UBC-808 population from lane 1-9. With $100 \mathrm{bp}$ Ladder

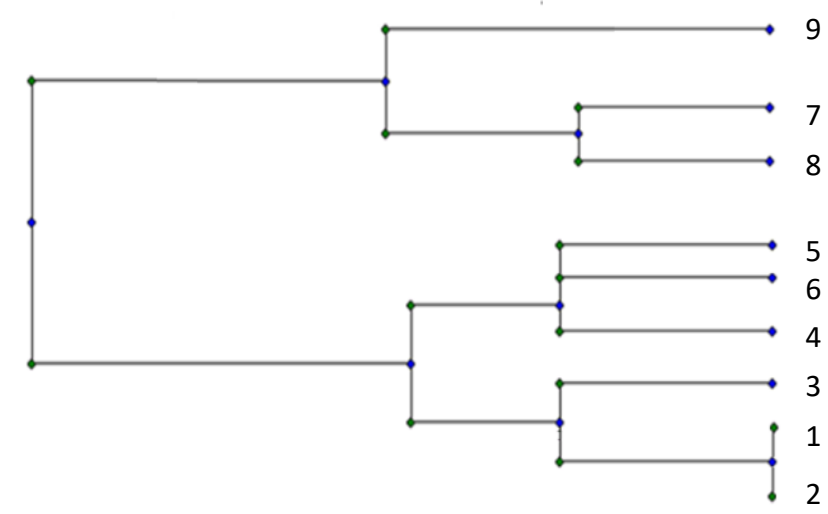

Figure 5. NTSYS- dendrogram of cluster analysis based on data generated from RAPD and ISSR among three different populations of Ephedra. Note: Plant sample code refer to Table 2.

The cluster-based on UPGMA tree (Figure 5) is delimited into two main clusters comprising $E$. major subsp. procera population (1-3) collected from Takatu Mountain Range and E. foliata (4-6) collected from Hazarganji-Chiltan National Park, conserved region. The second cluster comprises E. intermedia (7-9) collected from Nushki Desert area commonly called Janglat area.

Population of E. intermedia growing in the desert of Nushki, in north of Balochistan are differentiated from natural population growing on mountainous range of Balochistan. Besides, the populations of E. foliata growing in the mountains of Hazarganji-Chiltan National Park, the

Table 5. Analysis of Variance for Total Phenolic

\begin{tabular}{llllll}
\hline Source & DF & SS & MS & F & P \\
\hline C1 & 2 & 34.4702 & 17.2351 & 2.334 & 0.178 \\
Error & 6 & 44.3109 & 7.3852 & & \\
Total & 8 & 78.7811 & & & \\
\hline
\end{tabular}

conserved region are clearly differentiated from other $E$. major subsp. procera from Takatu Mountain Range.

\section{Chemical diversity}

All Ephedra accessions were analyzed for total phenolic contents (TPC) expressed as tannin equivalents and flavonoids contents as quercetin equivalent within and among populations (Figure 6). The TPC ranged from 40 to $46 \mathrm{mg} / \mathrm{g}$ within the population E. major subsp. procera (Takatu Mountain Range), 42 to $45 \mathrm{mg} / \mathrm{g}$ within the population of E. foliata Hazarganji-Chiltan National Park, and 45 to $51 \mathrm{mg} / \mathrm{g}$ within population of $E$. intermedia from Nushki. Variation was maximum among population $E$. major subsp. procera and E. foliata than within-population with highly significant difference $(\mathrm{p}<0.001)$ (Tables 5-6). Mean concentration of TPC across the populations was $45.16 \pm 2.32 \mathrm{mg} / \mathrm{g}$ whereas flavonoids showed diverse patterns within and among population. It ranged from 112 to $117 \mathrm{mg} / \mathrm{g}$ within population of E. major subsp. procera (Takatu Mountain Range), while in the population of $E$. foliata it ranged from 101-106 mg/g. Within the population of E. intermedia $127-135 \mathrm{mg} / \mathrm{g}$, total flavonoid content was assessed. Mean concentration of flavonoids across the populations was $116 \pm 2.19 \mathrm{mg} / \mathrm{g}$.

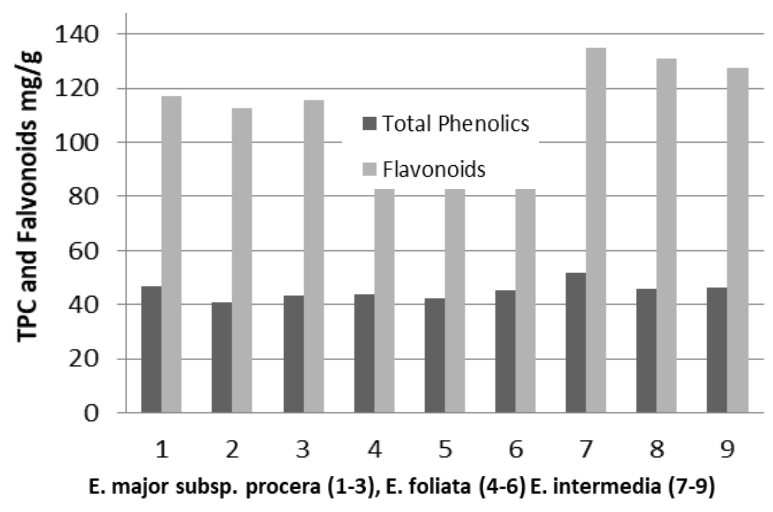

Figure 6. Patterns of phytochemical variations among different populations of Ephedra

Table 6. Analysis of Variance for Flavonoids

\begin{tabular}{llllll}
\hline Source & DF & SS & MS & F & P \\
\hline C1 & 2 & 1153.0467 & 576.5233 & 60.728 & 0.000 \\
Error & 6 & 56.9616 & 9.4936 & & \\
Total & 8 & 1210.0083 & & & \\
\hline
\end{tabular}




\section{Discussion}

The present investigation is based on genetic variability and population structure in three populations of Ephedra spp. naturally occurring in arid and semi-arid zones of Balochistan, Pakistan.

\section{Morphological diversity}

Morphological characters play an important role in identification and documentation of the taxa. Earlier studies were conducted explaining the morphological identification of Ephedra species from different regions (Bolinder et al. 2016). Present studies based on 14 morphological characters to study the interspecific relationships of Ephedra species present in Balochistan, Pakistan. From the present study results, it is evident that the three studied species of Ephedra from low elevation to high elevation zones exhibited morphological diversity. Earlier number of important species native to Pakistan were observed in various forms on exposed, dry rocks at altitudes ranging from 2500 to $5000 \mathrm{~m}$. A notable variation is found amongst the species due to varied geographical location, climate change, or any other influence by ecological diversity. Ephedra plant is a small woody, highly branched shrub, seldom exceeding $2 \mathrm{~m}$ in height; some species like $E$. foliata have a straggling or climbing stem, which is green, fistular, fluted, long jointed phylloclade, yellowish green to olive-green when young are in agreement with earlier explained morphology (Hayashi et al. 2019).

\section{Genetic diversity}

Ephedra is an important medicinal plant earlier few reports found on molecular analysis of this genus. In trends, few reports on medicinal plants diversity have been done on important cereal crops by using molecular markers. The pharmaceutical world needs to analyze the genetic makeup of Ephedra, as the genus is utilized for commercial and medicinal purposes by many industries. The current report on genetic makeup and diversity of selected three Ephedra species is novel in the region (low elevation to high elevation zones). E. procera genetic diversity was evaluated using RAPD and ISSR by (Saeed et al. 2015). In the present study a total of 20 RAPD and ISSR primers were used to elucidate the genetic structuring among three species of Ephedra. The use of combined marker reported earlier to detect polymorphism in wild plants of the area by (Saeed et al. 2020). The closest relation was found between $E$. procera and $E$. foliata, besides, low resemblance found in $E$. intermedia. Increased genetic variation with higher altitude provided genetic basis for the adaption to high altitude and low-temperature habitat (Hu et al. 2010) is in agreement with our findings.

\section{Chemical diversity}

The medicinal plants are of great therapeutic value and the components that are used in curing human diseases ( $\mathrm{Li}$ 2016). The Ephedra is an important medicinal plant earlier phytochemical analysis exhibited that the $E$. intermedia plant extract reported the presence of many phytochemicals like reducing sugars, cardiac glycoside, phenolic compounds, flavonoids, and alkaloids (Gul et al. 2017). Wild medicinal plants are used globally as folk medicines since human civilization can cure various ailments and reduce risks of chronic human illness, such as inflammation (Joshi and Pawar 2015). Currently, most prevailing and powerful drugs used were derived from medicinal plants based on their antioxidants originates from their ethnopharmacological utilization (Ullah et al. 2013). Many medicinal plant extracts constituted various types of chemicals like alkaloids, flavonoids, terpenoids, glycosides, tannins, etc. Our findings agreed with earlier phytochemical investigations of Ephedra species from different ecological zones of Pakistan.

Morphological, genetic and chemical variation found in studied species this conclusion is in line with identifying influence on environmental factors on plants secondary metabolites (Ahmed et al. 2020; Borges et al. 2017). A different factor influenced the diversity includes altitudinal gradient, climate change, soil type (deserted to mountainous rocks), and human/animal activities (Saeed et al. 2017; Ranya and Ahmed 2018).

In conclusion, the analysis of morphological variation and molecular polymorphism showed wider diversity among the three populations of Ephedra. Our results show that less diversity is observed among the Sra Gurgai population. It is assumed that this might be due to overcollection of the plant for its medicinal value. As it is an important plant used source of antioxidant and antimicrobial, hence its conservation is highly recommended otherwise these important medicinal plants would be near to extinction in future. Diversity in the Nushki region compared with the Takatu Mountain Range was higher and needs attention. Though the conserved regions of Hazarganji-Chiltan National Park still retained genetic diversity within populations, sustainable management plans are to be implemented. It has also been concluded that the assessment and conservation of genetic diversity through molecular markers is essential that could be used as a key to conserve genetic variability and assess environmental changes on allelic frequency. Furthermore, implementing conservation strategies for such significant wild taxa is highly recommended.

\section{ACKNOWLEDGEMENTS}

UBRF-17/018 UoB Quetta supported this research project. The authors declare that they have no conflict of interest.

\section{REFERENCES}

Abd El-Ghani MM, Huerta-Martínez FM, Hongyan L, Qureshi R. 2017. The Deserts of Pakistan. Plant Responses to Hyperarid Desert Environments. Springer, Berlin.

Aboukhalid K, Al Faiz C, Douaik A, Bakha M, Kursa K, Agacka-Mołdoch M, Machon N, Tomi F, Lamiri A. 2017. Influence of environmental factors on essential oil variability in Origanum compactum Benth. growing wild in Morocco. Chem Biodiv 14 (9): e1700158. DOI: $10.1002 / \mathrm{cbdv} .201700158$. 
Ahmad S, Alam K, Wariss H, Anjum S, Mukhtar M. 2014. Ethnobotanical studies of plant resources of Cholistan desert, Pakistan. Intl J Sci Res 3: $1782-1788$.

Ahmed A, Hameed A, Saeed S. 2020. Ecological distribution, morphological and molecular characterization of Zygophyllaceae from diverse ecological zones of Balochistan, Pakistan. AEER 18: 2445-2462.

Bolinder K, Norbäck Ivarsson L, Humphreys AM, Ickert-Bond SM, Han F, Hoorn C, Rydin C. 2016. Pollen morphology of Ephedra (Gnetales) and its evolutionary implications. Grana 5: 24-51.

Borges CV, Minatel IO, Gomez-Gomez HA, Lima GPP. 2017. Medicinal plants: Influence of environmental factors on the content of secondary metabolites. Medicinal Plants and Environmental Challenges. Springer, Nederland.

Gul R, Jan SU, Faridullah S, Sherani S, Jahan N. 2017. Preliminary phytochemical screening, quantitative analysis of alkaloids, and antioxidant activity of crude plant extract from Ephedra intermedia indigenous to Balochistan. Sci World J 2017: 5873648. DOI: $10.1155 / 2017 / 5873648$.

Hayashi H, Shukurova M, Oikawa S, Ohta M, Fujii I, Nasyrova F, Aliev K, Hisoriev H, Fattokhov I, Saidov M. 2019. Field Survey of Ephedra Plants in Central Asia (1). Characterization of Ephedra equisetina, Ephedra intermedia, and their putative hybrids collected in the Zaravshan Mountains of Tajikistan. Biol Pharmaceut Bull 42: 552560 .

Hu Y, Wang L, Xie X, Yang J, Li Y, Zhang H. 2010. Genetic diversity of wild populations of Rheum tanguticum endemic to China as revealed by ISSR analysis. Biochem Syst Ecol 38: 264-274.

Ibragic S, Sofić E. 2015. Chemical composition of various Ephedra species. Bosnian J Basic Med Sci 15: 21-27.

Joshi LS, Pawar HA. 2015. Herbal cosmetics and cosmeceuticals: An overview. Nat Prod Chem Res 3: 170. DOI: 10.4172/23296836.1000170

Kitani Y, Zhu S, Batkhuu J, Sanchir C, Komatsu K. 2011 Genetic diversity of Ephedra plants in Mongolia inferred from internal transcribed spacer sequence of nuclear ribosomal DNA. Biol Pharm Bull 34: 717-726

Li TS. 2016. Chinese \& Related North American Herbs: Phytopharmacology \& Therapeutic Values. CRC Press, Boca Raton, FL.

Ordonez A, Gomez J, Vattuone M. 2006. Antioxidant activities of Sechium edule (Jacq.) Swartz extracts. Food Chem 97: 452-458.

Ranya E-B, Ahmed DGA. 2018. Evaluation of genetic diversity in wild populations of Peganum harmala L., a medicinal plant. J Genet Eng Biotechnol 16: 143-151.

Saeed S, Ahmed A, Laghari S, Ali G, Begum S. 2020. Genetic and chemical variation of Seriphidium quettense an endemic taxon of two mountainous regions of Quetta, Pakistan. Appl Ecol Environ Res 18: 2413-2423.

Saeed S, Barozai MYK, Ahmed A, Tareen RB, Ali S. 2017. Impact of ecological diversity on genetic and phytochemical variation in Juniperus excelsa from high elevation zones of Quetta valley, Pakistan. Pak J Bot 49: 201-206.

Saeed S, Barozai YK, Ahmed A, Tareen RB, Ali GM, Shehzad A, Begum S. 2015. Genetic diversity of Ephedra procera from high altitudes of Quetta valley, Balochistan using RAPD and ISSR. Pak J Weed Sci Res 21 (2): 163-172.

Slinkard K, Singleton VL. 1977. Total phenol analysis: automation and comparison with manual methods. Am J Enol Viticult 28: 49-55.

Ullah M, Khan MU, Mahmood A, Malik RN, Hussain M, Wazir SM, Daud M, Shinwari ZK. 2013. An ethnobotanical survey of indigenous medicinal plants in Wana district south Waziristan agency, Pakistan. J Ethnopharmacol 150: 918-924.

Yaseen HS, Asif M, Saadullah M, Asghar S, Shams MU, Bazmi RR, Saleem M, Yousaf HM, Yaseen M. 2020. Methanolic extract of Ephedra ciliata promotes wound healing and arrests inflammatory cascade in vivo through downregulation of TNF- $\alpha$. Inflammopharmacology 28 (6): 1691-1704. 